\title{
Author’s Reply
}

To the Editor,

First of all, we thank the authors for their great interest in our work entitled "Effects of energy drinks on blood pressure, heart rate, and electrocardiographic parameters: An experimental study on healthy young adults" published in Anatol J Cardiol 2016; 16: 94-9 (1). In accordance to our discussion, they also notified the disparities between results of different studies on hemodynamic effects of energy drinks. For example, according to the literature, although Alford et al. (2) found no significant change in blood pressure (BP) after taking energy drinks, Steinke et al. (3) reported a significant BP rise. In addition, post-drink heart rate $(H R)$ was reported to be significantly dropped by Bichler et al. (4), whereas it was reported to be significantly increased by Steinke et al. (3). We mentioned that factors such as different fitness state and lifestyle of the study subjects, different types of energy drinks or different amounts of the same type of energy drink, and/or the different duration of post-consumption patient monitoring all might be playing a role for those discrepancies.

Considering the caffeine content of marketing energy drinks ranging from $50 \mathrm{mg}$ to $500 \mathrm{mg}(5)$, the authors of the letter stated that studying on doses as low as $80 \mathrm{mg}$ caffeine (used in our study) may not exert the hazardous effects of an energy drink with higher caffeine contents and other stimulants. As we have discussed in the article, we agree that different caffeine contents have different hemodynamic effects and thus the results of studies on low-caffeine energy drinks are not fully applicable to the cardiovascular effects of high-caffeine content beverages. Nevertheless, as we have mentioned in the article, a lower dose of caffeine has some specific hemodynamic effects itself, i.e., $H R$ is diminished after $<5 \mathrm{mg} /$ $\mathrm{kg}$ caffeine but is increased after higher doses. Moreover, we have described three literature-based possible explanations for HR decline after energy drink consumption, which confirms the importance of studying the cardiovascular effects of lowdose caffeine.

Finally, it is not possible to disagree with the authors of the letter mentioning that concurrent alcohol drinking or illicit drug abuse may increase the risk of consumption of caffeine-containing beverages. In our study, we excluded subjects with regular alcohol intake or those with a history of substance abuse but that issue might be focused on future investigations. 


\section{Shokoufeh Hajsadeghi}

Department of Cardiology, Rasoul Akram Hospital, Iran University of Medical Sciences, Tehran-Iran

\section{References}

1. Hajsadeghi S, Mohammadpour F, Manteghi MJ, Kordshakeri K, Tokazebani M, Rahmani E, et al. Effects of energy drinks on blood pressure, heart rate, and electrocardiographic parameters: An experimental study on healthy young adults. Anatol J Cardiol 2016; 16: 94-9.

2. Alford $\mathrm{C}, \mathrm{Cox} H$, Wescott $\mathrm{R}$. The effects of red bull energy drink on human performance and mood. Amino Acids 2001; 21: 139-50.

3. Steinke L, Lanfear DE, Dhanapal V, Klaus JS. Effect of "energy drink" consumption on hemodynamic and electrocardiographic parameters in healthy young adults. Ann Pharmacother 2009; 43: 596-602.

4. Bichler A, Swenson A, Harris MA. A combination of caffeine and taurine has no effect on short term memory but induces changes in heart rate and mean arterial blood pressure. Amino Acids 2006; 31: 471-6.

5. Turagam MK, Velagapudi P, Kocheril AG, Alpert MA. Commonly consumed beverages in daily life: do they cause atrial fibrillation? Clin Cardiol 2015; 38: 317-22.

Address for Correspondence: Shokoufeh Hajsadeghi, MD

Department of Cardiology, Rasoul Akram Hospital, Iran University of Medical Sciences, Tehran-Iran

Phone: (617) 919-6232

E-mail: fatemeh.touserkani@childrens.harvard.edu 